\title{
Tribute to Dirk Barends (1945-2010)— His Contributions to the FIP and the Regulatory Sciences
}

first met Dirk through the FIP in about 2000. We were both speakers at an FIP workshop in Vietnam, explaining to a Vietnamese audience how generic products are approved. In Dirk's role as a regulatory reviewer of applications to approve drug products for RIVM in the Netherlands, he had become interested in assuring that quality generic products could be brought to market at affordable prices, thus making medicines more accessible to people of all income levels throughout the world. For this reason, he joined the Special Interest Group of the FIP that deals with generic drug products, the Bioavailability and Bioequivalence Group.

A couple of years later, Dirk spearheaded a joint project between the FIP and WHO to apply the BCS Biowaiver concept to individual drug products. The idea was to assist national authorities and sponsors alike by creating Biowaiver Monographs, which would summarize the literature on a given active pharmaceutical product and draw a conclusion as to whether a marketing approval could be based on similarity between the dissolution properties of the proposed drug product and a comparator drug product already on the market. The first monograph, which covered drug products of verapamil, propranolol, and atenolol, was published in 2004. Shortly thereafter, Dirk served on a WHO panel to review its guidance on the approval procedures for generic drug products. The panel discussions crystallized the need to establish a set format for the Biowaiver Monographs, based not only on BCS considerations but also a risk/benefit analysis of applying the Biowaiver for each individual active pharmaceutical ingredient. After these interactions, Dirk invited me to join him to work on producing the Biowaiver Monographs, and our scientific partnership was cemented.

To generate the Biowaiver Monographs, Dirk selected a panel of fixed co-authors, including Gordon Amidon, Vinod Shah, Kamal Midha, Hans Junginger, Sol Stavchansky, and myself (all from the academic side), and Sabine Kopp (the scientific secretary of the Safety and Quality of Medicines division within the WHO), thus bringing on board stakeholders from the regulatory authorities along with experts in the fields of pharmacokinetics, bioequivalence, the Biopharmaceutics Classification System, and dissolution methodology. This group, with the help of some very capable first authors, produced a total of 24 Biowaiver monographs. In 2010, some changes were made to the group of fixed co-authors due to retirements and so forth, and the fixed co-authors then comprised Bertil Abrahamsson, Jennifer Dressman, Kik Groot, Sabine Kopp, Peter Langguth, James Polli, Vinod Shah, and Dirk Barends. In a period of just seven years, Dirk and his team published a total of 32 Biowaiver Monographs, and the pipeline is full.
In his role as Chair of the Special Interest Group (recently renamed the BCS and Biowaiver Focus Group), Dirk worked untiringly to apply the best possible scientific thinking to the task at hand, spurring all participants in the project not only to produce high quality monographs but also to challenge the regulatory guidances and suggest ways of improving

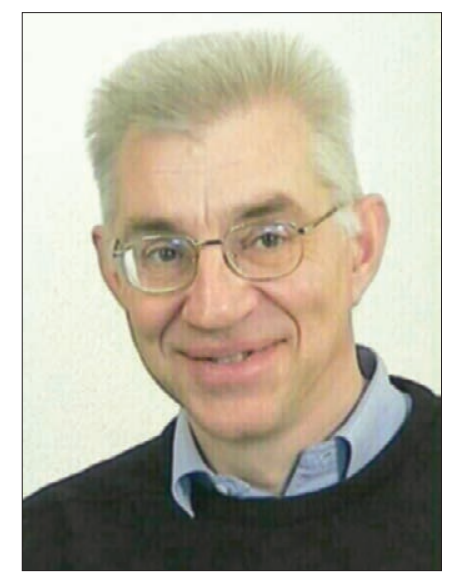
them. As the various guidances came up for revision, he stimulated the group to produce detailed commentaries on the draft versions. Many of these ideas were taken on board, and the result is better and more useful regulatory documents. This work is still ongoing as the U.S. FDA is currently considering revisions to its guidance.

The long-term intention is to provide monographs for all of the orally administered drug products on the WHO Essential Medicine List (EML). This will obviously take some years and a lot of effort, but will provide an excellent database for national authorities, for the WHO and NGOs as well as for pharmaceutical companies and researchers working with these compounds. Sadly, Dirk will not be there to finish the Biowaiver Monograph Project, but the rest of the author panel is dedicated to finishing what Dirk started and in this way pay him our deepest scientific respect.

For his untiring dedication to bioequivalence and in particular Biowaivers, Dirk was made a Fellow of the FIP in 2009. He also received a Certificate of Recognition from the FIP for his committee work in the Special Interest Group.

Of course, Dirk will be missed by his scientific colleagues for more than just his scientific input. In many ways, Dirk embodied the best Dutch characteristics - he was a straight shooter and you always knew where you stood with him on any issue. He was capable of enjoying the simple things in life- - a bike ride on a sunny day, a swim, a good discussion over a beer or a glass of wine with friends. He was a deeply loyal person, very supportive in difficult times and recognizing the importance of celebrating the good times. But I think most of all, we will miss Dirk's laugh—a big laugh, straight from the heart, that could fill an entire room.

Jenny Dressman, November 15t, 2012

For more information about BCS \& Biowaiver, and to view the monographs that have been published to date, please visit www.fip.org/bcs and www.fip.org/publications. 